\title{
Serum Ferritin and Gestational Diabetes Mellitus: A Case Control Study
}

\author{
Nilufar Islam ${ }^{1}$, Saleha Begum Chowdhury ${ }^{2}$
}

\begin{abstract}
Background \& objectives: Gestational diabetes mellitus (GDM) has been observed to be associated with increased perinatal morbidity and mortality. With the increase of diabetes mellitus worldwide, the incidence of GDM is also increasing. Increased serum ferritin, among others, has been identified as a risk for GDM. The present case-control study was conducted to determine the association between plasma ferritin level and risk of GDM.

Patients \& methods: The study was carried out in the Department of Obstetrics and Gynaecology in collaboration with Department of Biochemistry and Clinical Pathology, Bangabandhu Sheikh Mujib Medical University Hospital between January 2008 to December 2009. Pregnant women after 28 weeks of gestation and fasting plasma glucose level $>6$ $\mathrm{mmol} / \mathrm{L}$ and 2 hour after $75 \mathrm{gm}$ glucose ingestion $>7.8 \mathrm{mmol} / \mathrm{L}$ were included as cases. Pregnant women with multiple pregnancy, pregnancy with severe iron deficiency anaemia, and hemoglobinopathies were excluded from the study. A total 50 cases and 50 controls who met the respective eligibility criteria were included as sample.

Result: The mean ages of cases $(27.4 \pm 3.0$ years) and controls $(26.6 \pm 3.0$ years) were almost similar $(p=0.166)$. The family history of diabetes was significantly higher in case group than that control group (40\% vs. $20 \% ; p=0.029)$. Presence of overweight and obese subjects was higher in the case group than that in the control group $(p=0.038)$. The incidence of anaemia in cases was significantly lower $(8 \%)$ than that in control $(20 \%)(p=0.016)$. Over half $(52.2 \%)$ of the cases had history of gestational diabetes mellitus (GDM), $43.5 \%$ macrosomic baby and $17.4 \%$ stillborn baby or IUD, while only $2(9.5 \%)$ of the controls had past history of still-born baby or IUD. The mean serum ferritin was significantly higher in case group than that in control group $(36.5 \pm 17.6 \mathrm{vs} .19 .7 \pm 16.9 \mathrm{ng} / \mathrm{ml}, \mathrm{p}<0.001)$. A significantly linear correlation was observed between serum ferritin and 2 hours postparandial glucose $(r=0.392, p<0.001)$. More than $90 \%$ of the women having GDM exhibited elevated serum ferritin (>12 ng/ml) compared to $70 \%$ without GDM. The likelihood of having GDM is 5 times higher in pregnant women with high serum ferritin than that in low or normal serum ferritin ( $p=$ 0.009).
\end{abstract}

Conclusion: The study concludes that elevated serum ferritin serves as a predictor for development of GDM and the caring physicians or obstetricians should, therefore, be cautious enough in prescribing iron to the pregnant women.

Key words: Serum ferritin, gestational diabetes mellitus.

\section{Introduction}

Gestational diabetes mellitus (GDM) is defined as any degree of glucose intolerance with onset or first recognition during pregnancy. It occurs in 5 and $10 \%$ of all pregnancies. The hallmark of GDM is increased insulin resistance. ${ }^{1}$ Classical risk factors for developing gestational diabetes are maternal age (older than 35 years of age), history of type 2 diabetes in first degree relatives, a previous diagnosis of gestational diabetes or prediabetes or impaired glucose tolerance or overweight and obesity, a previous pregnancy which resulted in a child with a high birth weight (> 90th centile, or $>4 \mathrm{~kg}$ ). ${ }^{1}$

Gestational diabetes mellitus (GOM) increases the risk of macrosomia and perinatal morbidity and mortality for the fetus, while presaging a longterm risk of development of type-2 diabetes for the mother. ${ }^{2,3}$ In Chinese pregnant women, serum ferritin concentration was higher in women with impaired glucose tolerance and GDM. ${ }^{4,5}$ In a large cohort study in New Jersy, it was found that women who developed GDM had higher concentration of serum ferritin than women who

\section{Authors' Information:}

1. Dr. Nilufar Islam, Department of Obstetrics and Gynaecology, Bangabandhu Sheikh Mujib Medical University, Dhaka.

2. Prof. Dr. Saleha Begum Chowdhury, MBBS, FCPS (Obs \& Gynae), Department of Obstetrics \& Gynaecology, Bangabandhu Sheikh Mujib Medical University, Dhaka.

Correspondence: Dr. Nilufar Islam, Department of Obstetrics \& Gynaecology, BSMMU, Dhaka, Mobile: 01552-355691. 
did not develop GDM which persisted after adjustment for confounding variables like age and BMI. Elevated serum ferritin levels were associated with greater than two-fold increased risk of developing type-2 diabetes in the Finnish population. ${ }^{6}$ A strong association between higher serum ferritin concentration and newly diagnosed type-2 diabetes was observed among a US population as well. ${ }^{7}$

In our country maternal ferritin concentration in last trimester of pregnancy has never been categorically labeled as a risk factor for gestational diabetes mellitus (GDM). The present study was contemplated to address the hypothesis that high level of serum ferritin might be associated with gestational diabetes mellitus. The data generated from the study is likely to provide evidence on justification of the random use of iron in pregnancy which could be extrapolated to avert the chance of Gestational Diabetes Mellitus by avoiding routine iron supplementation in nonanaemic pregnant women.

\section{Patients \& Methods}

The present case-control study was conducted in the Department of Obstetrics and Gynaecology in collaboration with Department of Biochemistry and Clinical pathology, Bangabandhu Sheikh Mujib Medical University Hospital between January 2008 to December 2009 to determine the association between plasma ferritin level and risk of gestational diabetes mellitus (GDM). Pregnant women after 28 weeks of gestation and fasting plasma glucose level $>6 \mathrm{mmol} / \mathrm{L}$ or 2 hours postparandial glucose (after ingestion of $75 \mathrm{gm}$ of glucose) $>7.8 \mathrm{mmol} / \mathrm{L}$ were included as cases, while women with normal pregnancy were included as controls. Pregnant women with twin pregnancy, severe iron deficiency anaemia, preeclampsia, cardiac, hepatic or renal diseases or hemoglobinopathies were excluded from the study. A total 50 cases and 50 controls who met the respective eligibility criteria were included as sample. Data were analysed using SPSS version 11.5 and the test statistics used to analyse the data were Chi-square $\left(\chi^{2}\right)$, Student's t-Test and Spearman correlation. Odds ratio (with its 95\% confidence interval) for developing GDM in women with elevated serum ferritin was estimated. Level of significance was set at 0.05 and $p<0.05$ was considered significant.

\section{Resulf}

The mean ages of cases $(27.4 \pm 3.0$ years $)$ and controls ( $26.6 \pm 3.0$ years) were almost similar ( $p$ $=0.166$ ). Family history of diabetes was found significantly higher in case group than that in control group ( $40 \%$ vs. $20 \%$; $p=0.029$ ) (Table I). The incidence of anaemia in cases was significantly lower $(8 \%)$ than that in control $(20 \%)$ $(p=0.016)$. Oedema was found significantly higher in case group (52\%) compared to $20 \%$ in control group $(p=0.001)$. Over two-thirds $(68 \%)$ of the cases and $58 \%$ of the controls presented before 37 weeks of gestation. Over one-third of

\section{Table I. Comparison of demographics between cases and controls.}

\begin{tabular}{|c|c|c|c|}
\hline \multirow[b]{2}{*}{$\begin{array}{l}\text { Demographic } \\
\text { characteristics }\end{array}$} & \multicolumn{2}{|c|}{ Group } & \multirow[b]{2}{*}{$p$-value } \\
\hline & $\begin{array}{l}\text { Case } \\
(n=50)\end{array}$ & $\begin{array}{c}\text { Control } \\
(n=50)\end{array}$ & \\
\hline \multicolumn{4}{|l|}{ Age (yrs) ${ }^{\#}$} \\
\hline$<25$ & $9(18.0)$ & $12(24.0)$ & \\
\hline $25-30$ & $25(50.0)$ & $28(56.0)$ & \\
\hline$\geq 30$ & $16(32.0)$ & $10(20.0)$ & \\
\hline Mean \pm SD & $27.4 \pm 3.0$ & $26.6 \pm 3.0$ & 0.166 \\
\hline $\begin{array}{l}\text { Family history } \\
\text { of diabetes* }\end{array}$ & $20(40.0)$ & $10(20.0)$ & 0.029 \\
\hline
\end{tabular}

"Data were analysed using Student's t-Test; *Chi-square $\left(\chi^{2}\right)$. Test was done to analyse the data; figures in the parentheses indicate corresponding percentage.

Table II. Current clinical and obstetric characteristics between groups.

\begin{tabular}{|c|c|c|c|}
\hline \multirow{2}{*}{$\begin{array}{l}\text { Current clinical and obstetric } \\
\text { characteristics }\end{array}$} & \multicolumn{2}{|c|}{ Group } & \multirow[b]{2}{*}{ p-value\# } \\
\hline & $\begin{array}{c}\text { Case } \\
(n=50)\end{array}$ & $\begin{array}{l}\text { Control } \\
(n=50)\end{array}$ & \\
\hline Anaemia* & $4(8.0)$ & $10(20.0)$ & 0.016 \\
\hline Oedema ${ }^{\#}$ & $26(52.0)$ & $10(20.0)$ & 0.001 \\
\hline \multicolumn{4}{|l|}{ Gestational age (weeks)\# } \\
\hline$<37$ & $34(68.0)$ & $29(58.0)$ & 0.300 \\
\hline$\geq 37$ & $16(32.0)$ & $21(42.0)$ & \\
\hline \multicolumn{4}{|l|}{ Gravida $\#$} \\
\hline Primigravida & $31(62.0)$ & $19(38.0)$ & \\
\hline Multigravida & $33(66.0)$ & $17(34.0)$ & 0.677 \\
\hline Polyhydroamnios\# & $10(20.0)$ & 00 & 0.001 \\
\hline Preterm labour* & $3(6.0)$ & $2(4.0)$ & 0.691 \\
\hline PROM* & $5(10.0)$ & $4(8.0)$ & 0.500 \\
\hline
\end{tabular}

"Chi-square $\left(\chi^{2}\right)$ Test was done to analyse the data; *Fisher's Exact Test was done to analyse the data; figures in the parentheses denote corresponding percentage. 
the cases and controls were multigravida. Polyhydroamnios was found in $20 \%$ of cases, preterm labour in $6 \%$ and premature rupture of membrane (PROM) in $10 \%$. In the control group $4 \%$ was in preterm labour and $8 \%$ had PROM. None of the controls exhibited polyhydroamnios. All the current obstetric characteristics except polyhydroamnios were identical between groups $(p>0.05)$ (Table II). Over half $(52.2 \%)$ of the multigravidae cases had history of gestational diabetes mellitus (GDM), 43.5\% macrosomic baby and $17.4 \%$ stillborn baby or IUD, while only $9.5 \%$ of the controls had past history of still-born baby or IUD (Table III).

Table III. Comparison of past obstetric history between groups

\begin{tabular}{llll} 
Past obstetric history & \multicolumn{2}{c}{ Group } & p-value\# \\
& $\begin{array}{l}\text { Case } \\
(\mathbf{n}=23)\end{array}$ & $\begin{array}{l}\text { Control } \\
(\mathbf{n}=21)\end{array}$ & \\
\hline History of CDM\# & $12(52.2)$ & 00 & $<0.001$ \\
History of macrosomic baby & $10(43.5)$ & 00 & 0.001 \\
H/O still-born/IUD* & $4(17.4)$ & $2(9.5)$ & 0.165
\end{tabular}

${ }^{\#} \chi^{2}$ Test was done to analyse the data. "Fisher Exact Test was employed to analyse the data.

The serum ferritin was significantly higher in case group than that in control group $(36.5 \pm 2.5$ vs. $17.4 \pm 0.7 \mathrm{ng} / \mathrm{ml}, \mathrm{p}<0.001)$. The mean haemoglobin level was lower in control group compared to that in case group, although the difference between the groups was not statistically significant $(p=0.222)$ (Table IV). A positive correlation was observed between serum

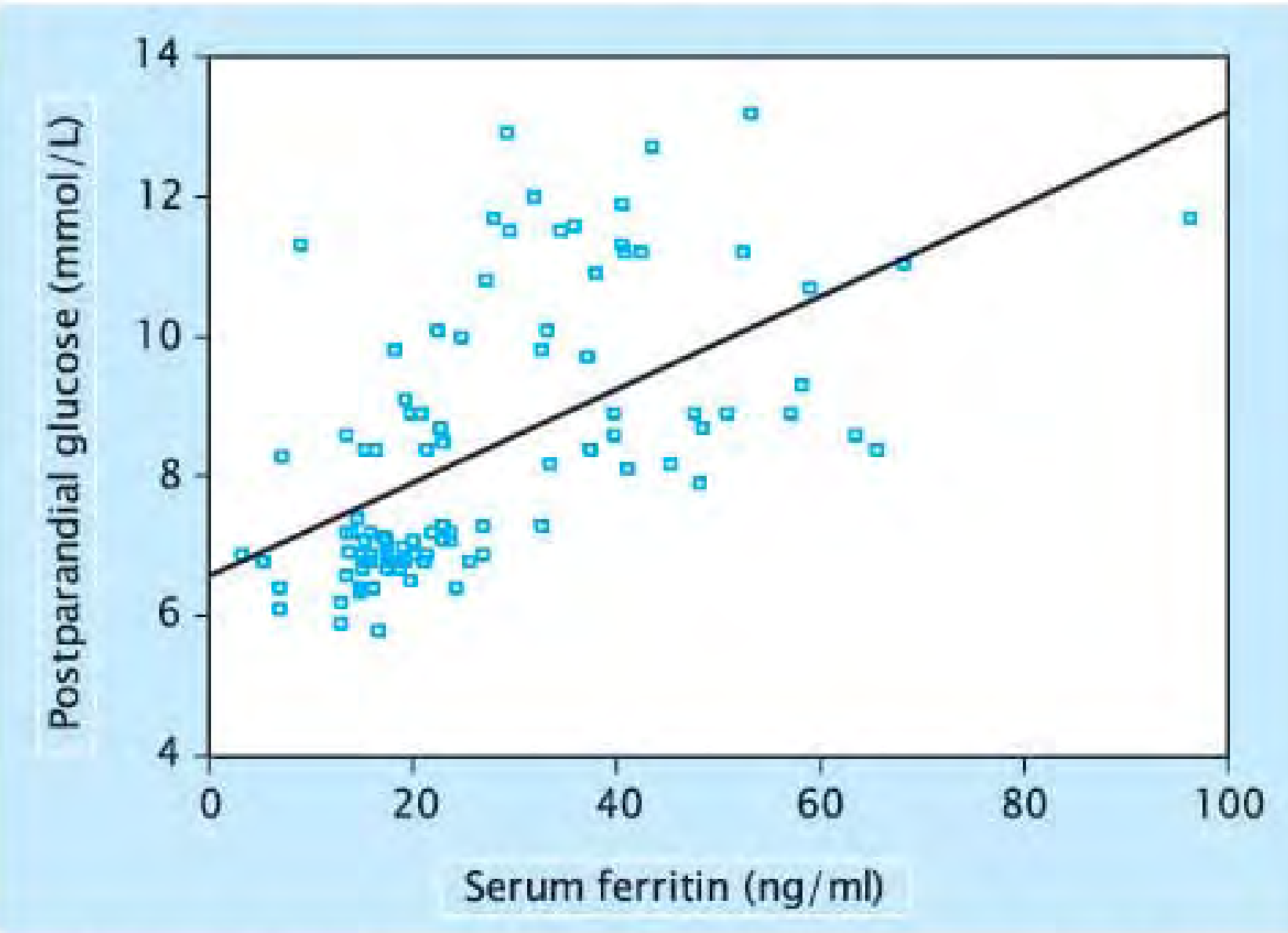

Fig. 1: Correlation between serum ferritin and fasting plasma glucose. ferritin and fasting plasma glucose level, though the correlation was not statistically significant $(r=0.131, p=0.193)$ (Fig. 1). However, a significantly linear correlation was evident between serum ferritin and serum plasma glucose 2 hours after $75 \mathrm{~g}$ of glucose ingestion $(r=0.392, \mathrm{p}<0.001)$ (Fig. 2). High serum ferritin was significantly common in women who developed GDM than those who did not develop the disease $(p<0.05)$. The risk of developing GDM among subjects who had elevated serum ferritin in early pregnancy was nearly 5 times $(95 \% \mathrm{Cl}=1.3-14.7)$ higher than those who did not have elevated serum ferritin ( $p=0.009$ ) (Table V).

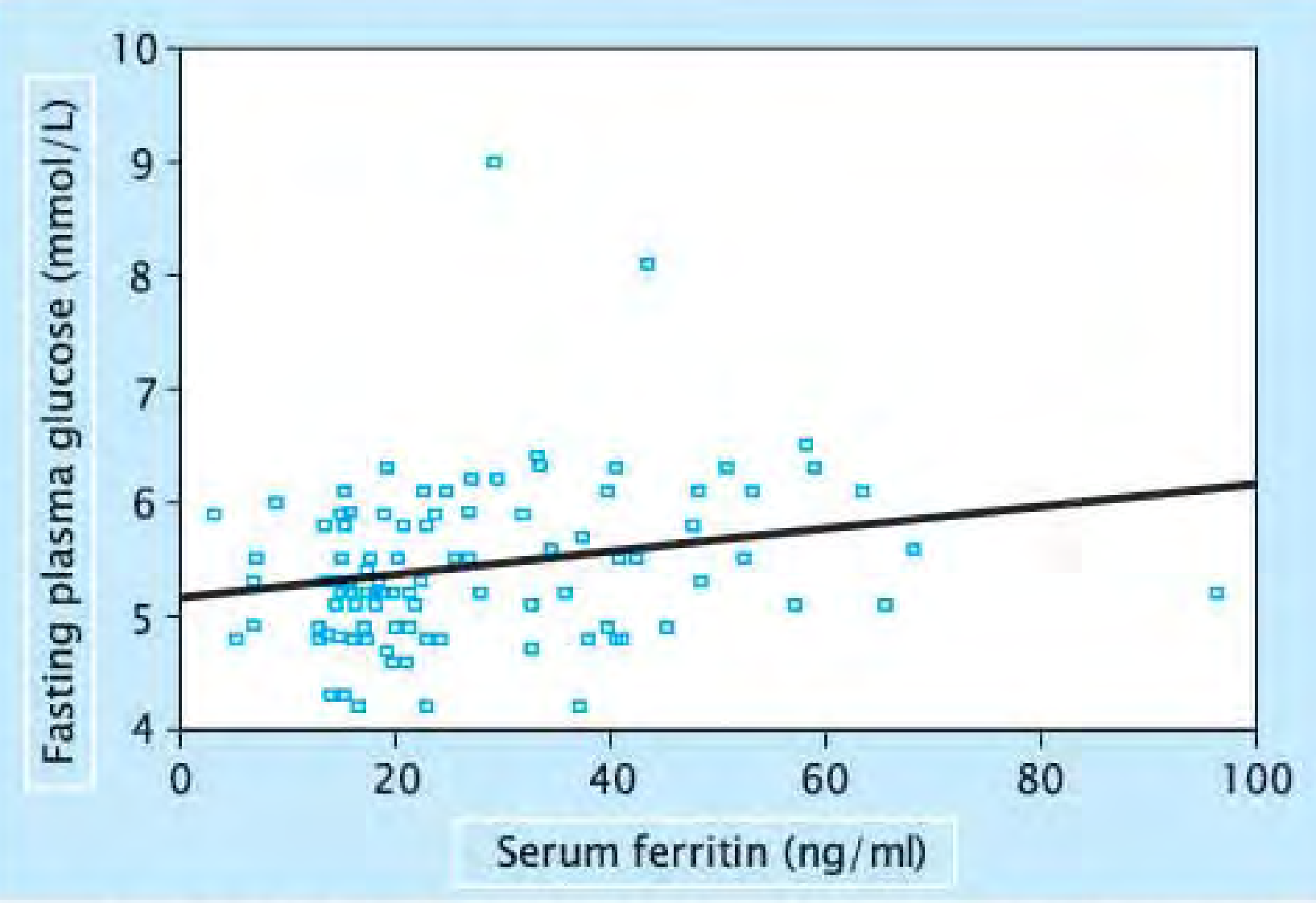

Fig. 2: Correlation between serum ferritin and postparandial plasma glucose.

Table IV. Comparison of biochemical parameters between groups.

\begin{tabular}{|c|c|c|c|}
\hline \multirow[b]{2}{*}{ Biochemical parameters } & \multicolumn{2}{|c|}{ Group } & \multirow[b]{2}{*}{ p-value $\#$} \\
\hline & $\begin{array}{l}\text { Case } \\
(n=23)\end{array}$ & $\begin{array}{l}\text { Control } \\
(n=21)\end{array}$ & \\
\hline Haemoglobin\# (g/dl) & $12.1 \pm 0.9$ & $10.7 \pm 0.8$ & 0.222 \\
\hline Serum ferritin ( $\mathrm{ng} / \mathrm{ml})$ & $36.6 \pm 2.5$ & $17.4 \pm 0.8$ & $3<0.001$ \\
\hline
\end{tabular}

Table V. Association between elevated serum ferritin and GDM.

\begin{tabular}{lllll}
$\begin{array}{l}\text { Serum ferritin } \\
(\mathrm{ng} / \mathrm{ml})\end{array}$ & $\begin{array}{c}\text { Case } \\
(\mathrm{n}=50)\end{array}$ & $\begin{array}{c}\text { Control } \\
(\mathrm{n}=50)\end{array}$ & $\mathrm{p}$-value & $\begin{array}{c}\text { Odds Ratio* } \\
(95 \% \mathrm{Cl})\end{array}$ \\
\hline 12 & $46(92.0)$ & $35(70.0)$ & & \\
$\leq 12$ & $4(8.0)$ & $15(30.0)$ & 0.009 & $4.7(1.3-14.7)$
\end{tabular}

"Data were analysed using $\chi^{2}$ Test; *Odds Ratio estimates the risk of developing GDM. Figures in the parentheses denote corresponding percentage. 


\section{Discussion}

The cases and controls were almost similar in terms of age, gestational age and parity, although pregnant women with GDM had a significantly higher frequency of obesity and significantly higher incidence of family history of diabetes than their control counterpart. In the present study more than $90 \%$ of the pregnant women having GDM exhibited elevated serum ferritin ( $>12$ $\mathrm{ng} / \mathrm{ml}$ ) compared to $70 \%$ of pregnant women without GDM. The likelihood having GDM is 4.7 times $(95 \% \mathrm{Cl}=1.3-14.7)$ higher in pregnant women with high serum ferritin than that in low or normal serum ferritin $(p=0.009)$. In a prospective observational study of 1,456 healthy pregnant women, serum ferritin and anthropometric measurements were determined in early pregnancy. ${ }^{8}$ Of them who subsequently developed GDM had a higher concentration of serum ferritin than women who did not develop GDM $(p<0.001)$. Women in the highest quartile of serum ferritin had a 2-fold increased risk of developing GDM adjusted for skin-fold thickness and prepregnant BMI. This study bears consistency with findings of the present study. Jiang and associates ${ }^{9}$ in a nested case-control study demonstrated that the mean concentration of serum ferritin among cases of incident diabetes was significantly higher compared with control subjects, and the relationship persisted after correction for various other risk factors for diabetes, including markers of obesity and inflammation. Similarly, high iron stores have been linked to insulin resistance, metabolic syndrome, and gestational diabetes. ${ }^{10}$ Besides these, there are some indirect evidences that increased serum ferritin concentrations or iron stores may be linked with gestational diabetes mellitus.

In a prospective observational study, 762 nondiabetic Chinese women with singleton pregnancies whose initial visit hemoglobin concentration $10 \mathrm{~g} / \mathrm{dL}$ or more were recruited at 28-30 weeks gestation. The women were categorized by their initial visit haemoglobin concentration into quartiles and the incidence of GDM was analyzed together with the maternal characteristics and iron status. Compared with rest, the group in the highest hemoglobin quartile $(>13 \mathrm{~g} / \mathrm{dL}$ ) had a significantly higher incidence of GDM $(18.7 \%$ versus $10.9 \%, p=0.007)$ After adjustment for the age, weight, serum ferritin and iron concentrations, advanced age and hemoglobin in the highest quartile were found to be the significant predictors of GDM (odds ratio 3.79 and 1.73 respectively). ${ }^{11}$ This study suggests that a high maternal hemoglobin (reflecting a high serum ferritin as well) early in pregnancy is an independent risk factor for subsequent development of GDM. The idea gleaned from these studies led to the testing of another hypothesis that iron deficiency anemia then may be an inhibiting factor for development of GDM in pregnant women. Accordingly in a retrospective case-control study ${ }^{12}, 242$ women with iron deficiency anemia $(\mathrm{Hb}<10 \mathrm{~g} / \mathrm{dl}$ with features of iron deficiency) were compared with 484 nonanemic women matched for age, maternal demographics and infant outcome. The findings showed that the anaemic group was less likely to develop GDM than their non-anaemic counterpart (odds ratio $=0.52,95 \% \mathrm{Cl} 0.27-0.97$ ) and the prevalence of GDM was observed to be significantly reduced with the increase in duration of anaemia $(p=0.045)$. Multiple logistic regression analysis was performed adjusting for the effects of multiparity and BMI, and anemia emerged as significant predictor for decreased prevalence of GDM (adjusted OR $=0.46,95 \% \mathrm{Cl}$ 0.23-0.90).

These findings warn us that indiscriminate prescribing of iron in pregnant mothers without assessing their level of haemoglobin or too much consumption of iron-rich food by the pregnant women themselves may predispose to the development of GDM by increasing the load of serum iron. However, there is dispute over the association between serum iron status and GDM as to whether serum iron is a cause or consequence insulin resistance. From Swaminathan et al ${ }^{10}$ reported that modest elevations in ferritin levels observed in diabetes may be a consequence or marker rather than the cause of impending insulin resistance and that elevated ferritin may not reflect elevated body iron store or an intracellular labile iron pool that participates in oxidant injury. 
Offsprings of diabetic mothers have a higher rate of infant morbidity compared to those born to non-diabetic mothers, 13 and this is characterized by excess macrosomia and operative delivery. 14 Perinatal mortality was also shown to be higher in the offsprings of the diabetic mothers compared to those without diabetes.15 These findings indicate that control of GDM is a must to reduce the perinatal morbidity and mortality.

The study concludes that high level of serum ferritin serves as an early predictor of gestational diabetes mellitus. As high level of haemoglobin corresponds to high serum ferritin and results from additional intake of iron, indiscriminate prescribing of iron without assessing the level of haemoglobin or serum iron parameters may cause more harm than good.

\section{References}

1. Gestational Diabetes. Detection, Management and Implications. Clinical Diabetes 1998; 16(1): 4.

2. American Diabetes Association. Gestational diabetes mellitus. Diabetes Care 2002; 23(Suppl 1) : S77-S79.

3. Clark CM, Qiu C, Amerman B, Porter B, Fineberg N, Aldasouqi $S$ et al. Gestational diabetes: should it be added to the syndrome of insulin resistance? Diabetes Care 1997; 20: 867-71.

4. Lao TT and Tarn KF. Maternal serum ferritin and gestational impaired glucose tolerance. Diabetes Care 1997; 20: 1368-9.

5. Lao $\Pi$ Chan PL and Tam KF. Gestational diabetes mellitus in the last trimester- a feature of maternal iron excess?', Diabet Med 2001; 18: 218-23.
6. Tuomainen TP, Nyyssonen K, Salonen R, Tervahauta A, Korpela H, Lakka T et al. Body iron stores are associated with serum insulin and blood glucose concentrations: population study in 1,013 eastern Finnish men. Diabetes Care 1997; 20: 426-8.

7. Ford ES and Cogswell ME. Diabetes and serum ferritin concentration among U.S. adults. Diabetes Care 1999; 22: $1978-83$.

8. Chen X, Scholl TO and Stein TP. Association of Elevated Serum JEerritin Levels and the Risk of Gestational Diabetes Mellitus in Pregnant Women, Diabetes Care 2006; 29: 1077-82.

9. Jiang R, Manson JE, Meigs JB, Ma J, Rifai N, Hu FB. Body iron stores in relation to risk of type 2 diabetes in apparently healthy women. JAMA 2004; 291: 711-7.

10. Swaminathan S, Fonseca VA, Alam MG, Fonseca VA. The role of iron in diabetes and its complications (review). Diabetes Care 2007; 30: 1926-33.

11. Lao TT, Chan LY, Tam K-F, Ho Lai-Fong. Maternal haemoglobin and risk of gestational diabetes mellitus in Chinese Women. Obstet \& Gynaecol 2000; 99: 807-12.

12. Lao $\Pi$ and Ho Lai-Fong. Impact of iron deficiency anaemia on prevalence of gestational diabetes mellitus. Diabetes Care 2002; 27: 650-6.

13. Nasrat HA, Salih M, Ardawi M, Ghafouri H. Outcome of pregnany in diabetic mothers. Int J Gynaecol Obstet 1993;10(8): 29.

14. Nasrat HA, Fageeh W, Abalkail B, Yamani T, Ardawi M. Determinant of pregnancy outcome in patients with gestational diabetes. Int J Gynaecol Obstet 1996; 53(2): 117.

15. Subande AA, Al-Bar A, Archibong EL 2000. Diabetes and perinatal loss. A continuing problem. Saudi Med J 2000; 21(2): 161-3. 